\title{
Saccharomyces boulardii in Acute Childhood Diarrhoea
}

\author{
Mandal A' ${ }^{1}$ Sahi PK ${ }^{2}$
}

\section{To the Editor,}

W e read with much interest the article by Dash et al., published in the recent issue of your journal ${ }^{1}$ but at the same time would like to make the following comments, clarification to which would benefit the general readers of JNPS.

The objectives of the study are stated to be "To evaluate the role of S. boulardii related to: Duration of diarrhoea, frequency of diarrhoea, complications, hospital stay, direct and indirect costs involved". But, firstly, the authors do not mention the primary objective; thus, it is not clear that how they had calculated the sample size of 126 ! It is very important as the power of the analysis depends on the sample size.

Secondly, though the 'indirect' and 'social' costs are mentioned in the two groups, no information is provided as to how they were calculated.

Thirdly, though hospital discharge is used as an outcome indicator, the criteria for discharge are not mentioned.

Fourthly, the conclusion mentions that use of $S$. boulardii "was not associated with any adverse effects as shown in our present study", but no such data is presented in the results.

The study being an interventional study, the authors should have provided greater details of the treatment received by the children in the two groups, such as the formulation of $S$. boulardii used and how it was administered. Also treatment apart from $S$. boulardii, such as the dose of zinc, the protocol for ORS (Oral rehydration solution) administration and requirement of intravenous fluid was not mentioned. Though, children who received prior antibiotics were excluded, there is no mention whether children receiving antidiarrhoeal drugs such as activated charcoal, bismuth, pectin, etc. were included in the study. The authors do not mention the definition/ criteria used for terminologies like "mild to moderate dehydration" and "severe diarrhoea".

Finally, being an 'open label' study, the possibility of 'observer bias' should have been acknowledged.

Response from Author: None

Response from Editor: Thank you for the feedback, we have tried to contact the authors but since they have not responded, we would like to appreciate your response and will try making sure that such mistakes do not happen in the future.
${ }^{1}$ Dr. Anirban Mandal, Department of Pediatrics, Sitaram Bhartia Institute of Science and Research, New Delhi, India, ${ }^{2}$ Dr. Puneet Kaur Sahi, Department of Pediatrics, Kalawati Saran Children's Hospital, New Delhi, India.

\section{Address for correspondence Dr. Anirban Mandal \\ E-mail: anirban.nrs@gmail.com}

\section{How to cite}

Mandal A, Sahi PK. Saccharomyces boulardii in Acute Childhood Diarrhoea. J Nepal Paediatr Soc 2017;37(2):207-208.

doi: http://dx.doi.org/10.3126/jnps.v37i2.17167

This work is licensed under a Creative Commons Attribution 3.0 License. 


\section{References}

1. Dash DK, Dash M, Mohanty MD, Acharya N. Efficacy of Probiotic Saccharomyces boulardii as an Adjuvant Therapy in Acute Childhood Diarrhoea. J Nepal
Paediatr Soc 2016;36(3):250-255. DOI: http://dx.doi. org/10.3126/jnps.v36i3.15539

2. Kadam $P$, Bhalerao S. Sample size calculation. Int $J$ Ayurveda Res 2010;1(1):55-7. DOI: 10.4103/09747788.59946 